\title{
建皿 BeleidsonderzoekOnline
}

\section{Respons en motivatiebronnen bij bedrijfsenquêtes}

\author{
Vanessa Torres van Grinsven
}

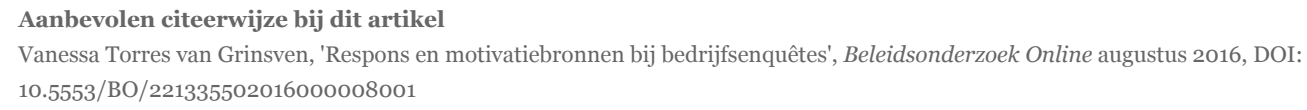

Bedrijven en andere organisaties worden vaak overladen met enquêtes en klagen over de lastendruk hiervan. Ook zijn de responsaantallen bij organisatie- en bedrijfsenquêtes de laatste decennia gedaald en hebben academici hun zorgen geuit over de kwaliteit van de respons (zie bijv. Baruch, 1999). In dit artikel bespreek ik onderzoek naar mogelijke strategieën om de motivatie van organisaties en hun respondenten te verhogen (zie Torres van Grinsven, 2015). Het doel van het verhogen van de motivatie is niet alleen de responsaantallen te verbeteren, maar ook de kwaliteit van de respons. Op basis van dit onderzoek komen wij tot een aantal aanbevelingen met betrekking tot het ontwerp van organisatie- en bedrijfsenquêtes, waaronder ook communicatieaspecten. Deze aanbevelingen zijn gericht op het verbeteren van de responsaantallen en de responskwaliteit bij enquêteonderzoek, maar ook op het verminderen van klachten over lastendruk door de bedrijven en organisaties. De focus is hier op zowel organisatie- als bedrijfsenquêtes, omdat het bij bedrijven ook kan gaan om eenmanszaken, die dus geen organisatie zijn; bij organisaties kan het gaan om organisaties die geen bedrijf zijn (d.w.z. organisaties die niet primair gericht zijn op winstbejag, zoals een school of een ngo).

\section{Samenvatting van het onderzoek}

Een van de motivatietheorieën die de laatste jaren de meeste aandacht heeft gekregen en veel in de praktijk toegepast wordt is de Self-Determination Theory, SDT (Ryan \& Deci, 2000). Deze theorie wordt veel toegepast in het onderwijs, maar is ook gebruikt om motivatie bij het invullen van persoonsenquêtes aan te pakken. De SDT gaat uit van twee soorten motivatie: de intrinsieke en de extrinsieke motivatie. Daarbij wordt gesteld dat het stimuleren van de intrinsieke motivatie de voorkeur heeft, aangezien deze tot betere resultaten zou leiden, wat zich uit in bijvoorbeeld betere prestaties. De drie fundamentele behoeftes die gerelateerd worden aan intrinsieke motivatie, zijn in deze theorie en de bijbehorende subtheorie Cognitive Evaluation Theory (Deci \& Ryan, 1980): competentie (competence), autonomie (autonomy) en verbondenheid (relatedness). Hierdoor wordt door aanhangers van deze theorie voornamelijk aandacht besteed aan het bevorderen van deze drie aspecten als bronnen van intrinsieke motivatie. In een eerste deelonderzoek deden wij een analyse van kwalitatieve interviews afkomstig van zowel primaire als secundaire databronnen, om te onderzoeken of deze theorie inderdaad geschikt is als toepassing om de motivatie bij organisatie- en bedrijfsenquêtes te verhogen. Deze kwalitatieve interviews bestonden uit interviews bij bedrijven, waarbij onder andere gevraagd werd naar de redenen waarom deze bedrijven wel of niet enquêtes invullen en hoe ze deze invullen. Deze interviews werden zowel in Nederland als in Slovenië afgenomen. De thematische analyse van de interviews leidde tot de conclusie dat binnen een bedrijf en voor het invullen van bedrijfsenquêtes extrinsieke motivatie evenveel aandacht verdient als intrinsieke motivatie. Wij zagen in de interviews namelijk bronnen voor extrinsieke motivatie naar voren komen als belangrijke reden om enquêtes in te vullen en deze ook goed in te vullen (dat wil zeggen bijvoorbeeld de juiste informatie opgeven en daar ook moeite voor doen). Wij zagen dus dat andere bronnen van motivatie, naast de drie bronnen competentie, autonomie en verbondenheid, relevant kunnen zijn. Dit in tegenstelling tot eerder onderzoek, dat dus voornamelijk aandacht gaf aan intrinsieke motivatie en deze drie gerelateerde fundamentele behoeftes. Een voorbeeld van een bron voor extrinsieke motivatie is het nut inzien van iets, in dit geval de enquêtes. Dit kan gaan om nut voor de respondent zelf, voor het bedrijf, of ook nut voor de maatschappij. Als bijvoorbeeld een respondent of zijn superieur het nut inzien van de enquêtes, omdat zij zelf de statistieken die hieruit voortvloeien voor hun bedrijfsmanagement gebruiken, dan zal dit via extrinsieke motivatie leiden tot het correct invullen van de enquêtes.

Extrinsieke motivatie wordt verdeeld in meerdere niveaus, variërend van volledig extrinsiek tot geïntegreerd (zie voor de Organismic Integration Theory (OIT) Deci \& Ryan, 1985; Torres van Grinsven et al., 2014: 580). Bij elk van deze niveaus passen weer specifieke bronnen die dit type motivatie stimuleren. Verschillende bronnen voor extrinsieke motivatie die wij hebben kunnen identificeren in onze data, zijn: de legale verplichting (in het geval van officiële enquêtes van het CBS, het Centraal Bureau voor de Statistiek); werktaken (bijv. zoals omschreven in een functieomschrijving); sociale verantwoordelijkheid: 'De overheid heeft data nodig om goed te kunnen functioneren' (Torres van Grinsven et al., 2014: 589), waarde voor zichzelf of voor het bedrijf, en een aantal andere bronnen (zie tabel). Al deze bronnen lijken van belang bij het invullen van de bedrijfsenquêtes, waardoor wij tot de conclusie komen dat SDT niet afdoende het responsgedrag van bedrijven kan uitleggen, noch voldoet bij het bedenken van manieren om de motivatie van bedrijfsrespondenten te verhogen.

Tabel 1 Bronnen van motivatie voor de responstaak bij bedrijfsenquêtes (aangepast van: Torres van Grinsven et al., 2014)

\begin{tabular}{|l|l|l|}
\hline Type motivatie & Subtypes motivatie & Bronnen voor motivatie \\
\hline Extrinsic motivation & Externally regulated motivation & Legal mandate \\
\hline & & Work tasks (explicitly assigned) Social responsibility: \\
& & \\
\hline
\end{tabular}




\begin{tabular}{|c|c|c|}
\hline & Introjected extrinsic motivation & $\begin{array}{l}\text { - Value for society in general } \\
\text { - Value for specific purposes } \\
\text { - Value for specific groups } \\
\text { - Principle of reciprocity }\end{array}$ \\
\hline & Identified extrinsic motivation & Value for own business or self \\
\hline & Integrated extrinsic motivation & Work tasks (adopted) \\
\hline Intrinsic motivation & & $\begin{array}{l}\text { Enjoyment and challenge } \\
\text { Perceived competence } \\
\text { Autonomy } \\
\text { Relatedness }\end{array}$ \\
\hline & & $\begin{array}{l}\text { Mood } \\
\text { Human curiosity disposition } \\
\text { Disposition for accuracy and precision } \\
\text { Routines } \\
\text { Task characteristics }\end{array}$ \\
\hline
\end{tabular}

Noot: de gecursiveerde termen zijn overgenomen van SDT en de subtheorieën Cognitive Evaluation Theory en Organismic Integration Theory.

Wij komen tot de conclusie dat andere benaderingen mogelijk sommige aspecten van motivatie bij het invullen van bedrijfsenquêtes beter uitleggen. Een voorbeeld kan zijn de benadering van McClelland (bijv. McClelland, 1985), een theorie die spreekt over impliciete en expliciete motieven.

In een tweede deelonderzoek onderzochten wij het gebruik van officiële statistieken door bedrijven, en mogelijkheden om dit gebruik te verbeteren. Hiervoor gebruikten wij wederom meerdere bronnen. Deze waren, onder andere, de kwalitatieve interviews bij bedrijven die al genoemd zijn als primaire data in het voorgaande deelonderzoek, kwalitatieve interviews bij brancheorganisaties, vertegenwoordigers van de Kamer van Koophandel, focusgroepen van experts bij statistiekbureaus die frequente contacten hadden met bedrijven over de bedrijfsenquêtes, maar ook andere data, zoals verzoeken voor informatie binnengekomen bij verschillende statistiekbureaus. Data werden verzameld in meerdere landen: Nederland, Noorwegen, Slovenië en Zweden.

Dit onderzoek laat zien dat bedrijven wel in meer of mindere mate gebruikmaken van officiële statistische data voor hun eigen bedrijfsvoering, maar dat dit gebruik ook zeker verbeterd kan worden. Er zijn namelijk een aantal duidelijke obstakels voor dit gebruik. Het eerste obstakel dat wij konden identificeren is dat er gebrek is aan besef van het bestaan en het nut van deze statistische data. Sommige bedrijven die deze data wel gebruiken, beseffen niet dat deze geproduceerd worden door de statistiekbureaus. Een ander probleem is de moeilijke toegankelijkheid van deze data. Zo blijkt dat veel mensen bij bedrijven niet de kennis hebben om deze data te vinden en, als ze al gevonden worden, ze te begrijpen en te interpreteren. Ten derde blijkt dat de data niet zo zijn opgesteld als gewenst door bedrijven. Zo vinden gebruikers van deze data bij bedrijven bijvoorbeeld dat deze data niet het gewenste detail hebben, maar te geaggregeerd en algemeen worden gepresenteerd; en dat deze data veel te laat beschikbaar worden gemaakt.

Op basis van deze onderzoeksresultaten hebben wij ook voorstellen voor verbetering opgesteld, met het dubbele doel om de capaciteit van nationale statistiekbureaus te verbeteren om statistieken te produceren die van hoge kwaliteit en relevant zijn voor bedrijven, en deze ook te communiceren; maar ook om het bewustzijn van bedrijven te verbeteren over de mogelijkheden die er zijn in het gebruik van officiële statistieken, om zo ook het gebruik te stimuleren. Zoals we zagen: als bedrijven meer het nut zien van statistieken, zullen zij ook meer gemotiveerd worden om mee te doen aan enquêtes die leiden tot deze statistieken. Deze voorstellen worden in deel 2 van dit artikel uiteengezet.

Een volgend deelonderzoek was een meta-analyse van 34 experimentele studies die een stimulans in de vorm van geld of een andere soort van extrinsieke beloning aanboden aan bedrijven of organisaties om responsaantallen te verhogen bij een enquête. Wat wij zien aan de hand van deze meta-analyse, is dat een extrinsieke beloning effectief is in het verhogen van de responsaantallen bij organisatie-enquêtes. Aan de andere kant waren we helaas niet in staat de tijdigheid en de kwaliteit van de respons te analyseren. Ook waren we niet in staat rechtstreeks de motivatie te meten om te zien welke vormen van motivatie door de extrinsieke beloning werden verhoogd. Er is vervolgonderzoek nodig om na te gaan of een extrinsieke beloning effect heeft op de kwaliteit van de respons (non-respons van enquêteonderdelen en meetfouten), en de responssnelheid. Er is ook vervolgonderzoek nodig om rechtstreeks te meten wat de exacte invloed is die extrinsieke beloning heeft op de verschillende soorten van motivatie. Op basis van eerdere onderzoeken (bijv. Deci et al., 1999) zouden wij kunnen aannemen dat een extrinsieke beloning invloed heeft op de extrinsieke motivatie. Het zou echter interessant zijn te bekijken of en in hoeverre een extrinsieke beloning invloed heeft op de intrinsieke motivatie. Andere onderzoeken geven namelijk tegenovergestelde resultaten aan die van Deci et al. (1999), namelijk dat extrinsieke beloningen niet per se negatieve effecten hebben op de intrinsieke 
motivatie (zie bijv. Cameron et al., 2001, voor een review zie Torres van Grinsven, 2015, hoofdstuk 6).

In het deelonderzoek met kwalitatieve interviews identificeerden wij sentimenten (zoals de stemming van een respondent) maar ook percepties (zoals de gepercipieerde waarde van een enquête of van de organisatie die de enquête heeft verstuurd) als belangrijke bronnen van motivatie bij het invullen van bedrijfsenquêtes (zie tabel 1). Als vervolg hierop deden wij onderzoek naar uitingen in de sociale media door bedrijven, en naar percepties en sentimenten die hieruit naar voren kwamen ten opzichte van het CBS en diens bedrijfsenquêtes. Hieruit kwam naar voren dat bepaalde acties en communicatiestrategieën van het CBS een positief of een negatief sentiment tot gevolg hadden. Dit onderzoek naar uitingen in de sociale media maakte in het bijzonder duidelijk dat communicatie heel belangrijk is bij het beïnvloeden van percepties en sentimenten, terwijl deze weer invloed hebben op het (respons)gedrag. Bij het ontwerpen van een enquête is het dus heel belangrijk ook gepaste aandacht te besteden aan het communicatieontwerp.

Ten slotte biedt het laatste deelonderzoek een kritisch overzicht van motivatieonderzoek en motivatietheorieën uit verschillende onderzoeksgebieden, mede gerelateerd aan de bevindingen uit de eerdere deelonderzoeken. Deze revisie biedt een nieuw perspectief op de drijfveren achter responsgedrag bij organisatie-enquêtes en het functioneren van extrinsieke beloningen binnen de omlijsting van een organisatie. In het bijzonder laten we het belang zien van extrinsieke motivatie en de aanverwante expliciete doelen en motieven en hun potentiële invloed op impliciete motieven. Naast de cognitieve en bewuste determinanten (de extrinsieke motivatie en expliciete doelen) bespreken we ook de invloed van impliciete motieven. Ook wijzen we naar de prominente rol van het stellen van doelen, iets wat typisch is in werkomgevingen en veel meer expliciet aanwezig is bij organisatie-enquêtes dan bij persoonsenquêtes.

\section{Praktische aanbevelingen voor het ontwerp van organisatie-enquêtes}

De praktische aanbevelingen die voortkomen uit dit onderzoek, zijn erop gericht een organisatie- of bedrijfsenquête inclusief de communicatie zo aan te passen dat de motivatie verhoogd kan worden. De verwachting is dat deze hogere motivatie dan weer zal leiden tot hogere responsaantallen, een snellere respons, nauwkeurigheid, en ook volledigheid van de respons.

Ten eerste zijn er enkele aanbevelingen over enquêteontwerp en communicatiestrategieën om de motivatie te verhogen. Om de responsaantallen te stimuleren gebruiken de statistiekbureaus bij officiële (en dus verplichte) bedrijfsenquêtes een aantal negatieve stimulansen. Het gaat hier om herinneringen en (de dreiging van) boetes in het geval van non-respons. Deze maatregelen lijken hun doel te bereiken, en het advies is dus om deze niet op te geven. Het is echter mogelijk om deze aan te vullen met meer positieve stimulansen. Om de extrinsieke motivatie te verhogen kunnen de waarde van een enquête, de enquêterende organisatie en de uitkomsten van de enquête voor de respondenten verhoogd worden, en ook is het belangrijk om deze waarde beter te communiceren naar de bedrijven en respondenten toe. Deze verhoging geldt dus voor zowel de gepercipieerde als de feitelijke waarde. Bijvoorbeeld, om de feitelijke waarde te verhogen kunnen, voor zover dat mogelijk is, de resulterende statistieken aan de wensen van de deelnemende bedrijven worden aangepast, oftewel 'customized'. Bij de gepercipieerde waarde gaat het erom dat deze waarde uitgelegd wordt aan de bedrijven, zodat zij deze waarde ook echt gaan inzien.

Daarnaast geven wij een aantal tips om de intrinsieke motivatie van de respondenten te verbeteren: het meedoen aan een enquête zou zo plezierig mogelijk gemaakt moeten worden; de gepercipieerde competentie (of gepercipieerde bekwaamheden) van de respondenten zou versterkt moeten worden; er zou een goede relatie tussen de bedrijven en de respondenten en de enquêterende organisatie opgebouwd moeten worden ter versterking van de verbondenheid; en respondenten zouden het gevoel moeten krijgen een zekere autonomie te hebben in relatie tot het invullen van de bedrijfsenquêtes. Het gaat hierbij dus onder andere om het versterken van de drie bronnen voor intrinsieke motivatie die eerder genoemd werden in het kader van de Self-Determination Theory.

Voor wat betreft het plezier in het invullen van een enquête bijvoorbeeld kan worden gedacht aan 'gamification'. Gamification houdt in dat elementen uit videogames, zoals spellen gespeeld op gameconsoles, toegevoegd worden aan in dit geval een bedrijfsenquête. Deze elementen kunnen bijvoorbeeld zijn: het toevoegen van avatars, het geven van feedback tijdens het invullen van de vragenlijst, en het toevoegen van tijdsdruk (zie Cechanowicz et al., 2013). Een goede relatie kan worden opgebouwd door het gebruik van accountmanagers of andere contactpersonen. Een zeker gevoel van autonomie kan bijvoorbeeld bereikt worden door de bedrijven kleine aanpassingen in de uiterste opleverdatum toe te staan.

Nog een mogelijke aanpak om de motivatie te verhogen zou kunnen zijn de stemming van de respondent te beïnvloeden. Ook zouden de uitkomsten van de bedrijfsenquête verbeterd kunnen worden als die respondenten geselecteerd zouden worden die de gewenste karaktereigenschappen hebben. Het kan hier gaan om mensen met een 'accuracy motivated' persoonlijkheid, mensen die vanuit hun impliciete motieven geneigd zijn zaken nauwkeurig af te werken. Er is vervolgonderzoek nodig om te kunnen bepalen hoe dit het beste gedaan zou kunnen worden. Het lijkt bijvoorbeeld zo dat mensen met bepaalde functies in organisaties meer geneigd zijn bepaalde karaktereigenschappen te hebben, die het nauwkeurig invullen van bedrijfsenquêtes positief beïnvloeden. De stemming van de respondent kan positief beïnvloed worden door bijvoorbeeld grappige elementen in de vragenlijst in te bouwen; hierbij kun je ook weer denken aan gamification en elementen daaruit.

Vervolgens toont ons onderzoek aan dat nationale statistiekbureaus bedrijven niet genoeg identificeren als een aparte belangrijke doelgroep. Hierdoor nemen deze instellingen de behoeftes van bedrijven zelden in overweging als een afzonderlijk en erkend belang. De onderzochte bedrijven waren in het algemeen slechts beperkt bewust van de nationale statistiekinstellingen als een bron voor externe data, onafhankelijk van het niveau van afhankelijkheid van data binnen het bedrijf. Er zijn drie zaken die verder gebruik van officiële statistieken binnen bedrijven in de weg lijken te staan: gebrek aan kennis over het feit dat sommige nuttige statistieken te vinden zijn bij een nationaal statistiekbureau (waarbij zowel bewustzijn als bekwaamheid een rol speelt), moeilijkheden met de toegankelijkheid van de statistieken, en tekortkomingen van de statistieken. De geïdentificeerde tekortkomingen waren van verschillende aard en met verschillende aspecten: interne en externe data sluiten niet op elkaar aan, officiële statistieken hebben niet voldoende detail, ze worden pas lang na de dataverzameling gepubliceerd, er waren behoeftes aan multinationale statistieken waar niet in voorzien werd, en ook zagen wij dat bedrijven de statistieken onvoldoende begrepen. Op basis van deze resultaten zouden nationale statistiekbureaus dus aangespoord moeten worden om de communicatie met de gebruikers van officiële statistieken te verbeteren. Op deze manier kunnen de statistiekbureaus zowel hun capaciteit om bedrijven en andere doelgroepen te helpen verbeteren, alsook de statistiekproductie. Wij verwachten namelijk dat op deze manier het gepercipieerde belang en het nut van de enquêtes voor bedrijven verhoogd wordt. Dit zijn bronnen voor extrinsieke motivatie en er wordt verondersteld dat deze zullen leiden tot betere enquête-uitkomsten. Concrete voorstellen omvatten het verspreiden van officiële statistieken op een manier die meer aangepast is aan de behoeftes en ervaringen van bedrijven en ondersteuning van bedrijven om officiële statistieken beter te kunnen gebruiken. 
Deze bevindingen zijn ook toepasbaar op andere onderzoeksinstellingen of organisaties die enquêtes versturen, voor zover zij hiervoor de middelen hebben. Het blijkt belangrijk te zijn om bij het opzetten van een enquête ook te kijken naar hoe de waarde van deze enquêtes wordt gecommuniceerd naar de bedrijven of organisaties toe die de enquêtes moeten invullen, en dat het ook belangrijk is de resulterende data op een voor de bedrijven nuttige manier te presenteren.

We stellen ook twee bredere actiepunten voor de nationale statistiekbureaus voor. Ten eerste meer samenwerking met tussenpersonen (bijv. de media of brancheorganisaties) die officiële statistieken verspreiden. Dit kan het bewustzijn versterken dat het nationale statistiekbureau de bron is van de statistieken en zo kunnen ook meer bedrijven geïnformeerd worden over voor hun relevante statistieken. Ten tweede: het zou zowel voor bedrijven als voor nationale statistiekbureaus voordelig zijn om de interne data van bedrijven en externe data van nationale statistiekbureaus meer in formaat en specificaties op elkaar te laten lijken. Het niet aansluiten van interne en externe data kan veroorzaakt zijn door verschillende standaarden in de verschillende overheidstakken (bijv. boekhouding, statistieken, douane). Pogingen om zulke verschillen te verminderen of zelfs helemaal weg te nemen zijn bijvoorbeeld het gebruik van 'single entry points' voor bedrijven die hun data via deze 'single entry points' kunnen verstrekken aan overheidsinstellingen (bijv. Yancheva \& Iskrova, 2011; Pereira, 2011), en unificerende dataformats (bijv. Van Hilvoorde, 2011).

Van de meta-analyse van het gebruik van extrinsieke beloningen bij een organisatie-enquête leiden we af dat het gebruik van extrinsieke beloningen tot betere responsaantallen kan leiden bij organisatie-enquêtes, en dan vooral als de responsaantallen normaal gesproken laag zijn. De resultaten van deze meta-analyse ondersteunen de eerder besproken bevindingen die laten zien dat extrinsieke motivatie belangrijk is bij het invullen en beantwoorden van bedrijfsenquêtes. Op basis hiervan adviseren wij om extrinsieke beloningen te gebruiken in organisatie-enquêtes, afhankelijk van de gebruikelijke responsaantallen en een vooranalyse van de kosteneffectiviteit en andere specifieke interesses in elk afzonderlijk geval. Vooral bij lagere verwachte responsaantallen is een extrinsieke beloning effectief. Voorbeelden van extrinsieke beloningen kunnen zijn: kleine cadeautjes, zoals een usb-stick met het logo van bijvoorbeeld de gemeente die de enquête rondstuurt, een pen met zo'n logo, een cadeaubon, enzovoort.

Gebaseerd op de resultaten van de analyse van uitingen in de sociale media, kunnen wij ook een aantal aanbevelingen doen om de oorzaken van negatieve sentimenten weg te nemen, een positieve perceptie van het nationale statistiekbureau en de enquêtes te versterken, en daarmee de motivatie om mee te doen aan de enquêtes te verhogen om zo responsaantallen en de kwaliteit en tijdigheid van de respons te verhogen. Sommige van deze aanbevelingen zijn een herhaling van de bevindingen van de andere deelonderzoeken, waarmee deze dan ook weer worden bevestigd. Deze resultaten kunnen ook gebruikt worden door andere organisaties of instituten die enquêtes versturen, zoals gemeentes of onderzoeksbureaus.

Aangezien de kosten in tijd en geld belangrijk zijn voor ondernemers, is het belangrijk de kosten van de deelname aan een enquête zo veel mogelijk te verlagen, maar tegelijkertijd ook de (gepercipieerde) waarde, of het (gepercipieerde) nut, van de enquêtes te verhogen voor de bedrijven. Dat wil zeggen, dat bijvoorbeeld de enquêtes zo ontworpen worden dat de bedrijven zo weinig mogelijk tijd hoeven te steken in het beantwoorden van de enquêtes. In dezelfde lijn is het erg belangrijk de responstaak te vergemakkelijken en simplificeren, om zo de moeite die erin gestoken moet worden en daarmee de (gepercipieerde) kosten te verlagen. Daarnaast is het belangrijk dat de waarde en het nut van de enquêtes bekender worden gemaakt door middel van een geschikte en coherente communicatiestrategie (zie ook Snijkers, 2009; Snijkers et al., 2013). Een laatste set van aanbevelingen gaat over het gebruik van de sociale media. De sociale media kunnen worden gebruikt om statistieken te publiceren, maar ze kunnen ook gebruikt worden om met respondenten te communiceren en als een communicatiekanaal om een positieve perceptie van de enquêterende organisaties te stimuleren.

\section{Vervolgonderzoek}

Er is vervolgonderzoek nodig om meer in detail kennis op te doen over instrumenten en strategieën om de besproken types van motivatie en de bijbehorende bronnen van motivatie zo goed mogelijk te gebruiken in een enquête- en communicatieontwerp. In zo'n vervolgonderzoek kunnen dan ook de precieze effecten van deze bronnen en types van motivatie op het responsgedrag en de uitkomsten van bedrijfsenquêtes worden getest. Zo zou bijvoorbeeld de effectiviteit van een extrinsieke beloning als bron van extrinsieke motivatie experimenteel kunnen worden getest, en ook de invloed van een extrinsieke beloning op de intrinsieke motivatie. Ook het gebruik van de andere genoemde bronnen van extrinsieke en intrinsieke motivatie kunnen experimenteel worden getest. Het zou dus heel interessant zijn experimenten uit te voeren op het enquête- en communicatieontwerp van organisatie- en bedrijfsenquêtes waarbij strategieën toegepast kunnen worden zoals het 'gamificeren' van een bedrijfsenquête, om dan de precieze effecten op responsaantallen, kwaliteit van de data, snelheid van de respons, maar ook de verschillende types motivatie te meten.

Een mogelijke manier om intrinsieke en extrinsieke motivatie te meten, en zo dus het precieze effect op de motivatie te meten van de verschillende soorten bronnen van motivatie in een enquête en communicatieontwerp, is het toepassen van een van de verschillende motivatieschalen die zijn ontwikkeld in eerder onderzoek. Zie bijvoorbeeld: SIMS, Situational Motivation Scale (Guay et al., 2000); PLOCQ, Perceived Locus of Causality scale (Goudas et al., 1994); de schaal voor Werk Motivatie gebruikt door Wright (2004); en verschillende andere motivatieschalen die zijn ontwikkeld in de context van de Self-Determination Theory, waaronder de IMI (Intrinsic Motivation Inventory).

\section{Tot slot}

Meer informatie over dit onderzoek en de resultaten zijn onder andere te vinden in het proefschrift van de auteur (Torres van Grinsven, 2015). Dit proefschrift geeft theoretische en empirische inzichten in het concept van motivatie in verband met organisatie- en bedrijfsenquêtes. Met deze kennis kunnen de motivatie van bedrijven, organisaties en hun respondenten voor organisatie- en bedrijfsenquêtes verbeterd worden. Ook is er een theoretische basis gelegd om op voort te bouwen met verder onderzoek naar motivatie bij organisatie- en bedrijfsenquêtes. Belangrijk lijkt ook om zo goed mogelijk het gat te dichten tussen wat bekend is in andere disciplines over motivatie en de toepassing van deze kennis op enquêteonderzoek bij bedrijven en organisaties.

\section{Literatuur}

Baruch, Y. (1999). Response rate in academic studies: A comparative analysis. Human Relations, 52, 421-438. 
Cameron, J., Banko, K.M., \& Pierce, W.D. (2001). Pervasive negative effects of rewards on intrinsic motivation: The myth continues. The Behavior Analyst, 24, 1-44.

Cechanowicz, J., Gutwin, C., Brownell, B., \& Goodfellow, L. (2013). Effects of gamification on participation and data quality in a real-world market research domain. In Proceedings of Gamification 2013, DOI: 10.1145/2583008.2583016.

Deci, E.L., Koestner, R., \& Ryan, M.R. (1999). A meta-analytic review of experiments examining the effect of extrinsic rewards on intrinsic motivation. Psychological Bulletin, 125, 627-668.

Deci, E.L., \& Ryan, R.M. (1980). The empirical exploration of intrinsic motivational processes. In L. Berkowitz (Ed.), Advances in Experimental Social Psychology (Vol. 13, pp. 40-80). New York/London: Academic Press.

Deci, E.L., \& Ryan, R.M. (1985). Intrinsic motivation and self-determination in human behavior. New York: Plenum.

Eurostat. (2011). European Statistical Code of Practice. Eurostat, Luxembourg. Available at: http://ec.europa.eu/eurostat/web/products-manuals-and-guidelines/-/KS-32-11-955

Goudas, M., Biddle, S., \& Fox, K. (1994). Perceived locus of causality, goal orientations, and perceived competence in school physical education classes. British Journal of Educational Psychology, 64, 453-463.

Guay, F., Vallerand, R.J., \& Blanchard, C (2000). On the assessment of situational intrinsic and extrinsic motivation: The Situational Motivation Scale (SIMS). Motivation and Emotion, 24, 175-213.

IMI, Intrinsic Motivation Inventory, http://www.selfdeterminationtheory.org/intrinsic-motivation-inventory/

McClelland, D.C. (1985). How motives, skills and values determine what people do. American Psychologist, 40, 812-825.

Pereira, H.J. (2011). Simplified business information (IES): Is coordination between public entities really possible? In D. Giesen \& M. Bavdaž (Eds.), Proceedings of the BLUE-ETS Conference on burden and motivation in official business surveys. Statistics Netherlands, Heerlen, Netherlands. Available at: http://www.cbs.nl/NR/rdonlyres/23FD3DF5-6696-4A04-B8EF1FAACEAD995C/o/2011proceedingsblueets.pdf

Ryan, R.M., \& Deci, E.L. (2000). Intrinsic and extrinsic motivations: Classic definitions and new directions. Contemporary Educational Psychology, 25, 54-67.

Snijkers, G. (2009). Getting Data for (Business) Statistics: What's new? What's next? Paper presented at the 2009 NTTS Conference (New Techniques and Technologies for Statistics). Brussels, Belgium. Available at:

http://epp.eurostat.ec.europa.eu/portal/page/portal/research_methodology/documents/S5P2_GETTING_DATA_FOR_STATISTICS_SNIJKE

Snijkers, G., Haraldsen, G., Jones, J., \& Willimack, D. (2013). Designing and conducting business surveys. Hoboken: John Wiley and Sons.

Torres van Grinsven, V. (2015). Motivatie in responsgedrag bij bedrijfsenquêtes: Beïnvloeding van motivatie ter verbetering van enquêteuitkomsten. Proefschrift, Universiteit Utrecht. Beschikbaar via:

http://dspace.library.uu.nl/bitstream/handle/1874/317822/Torres_van_Grinsven.pdf?sequence=1

Torres van Grinsven, V., Bolko, I., \& Bavdaž, M. (2014). In search of motivation for the business survey response task. Journal of Official Statistics, 30, 579-606.

Van Hilvoorde, M. (2011). Standard business reporting programme: A Netherlands government initiative. In D. Giesen \& M. Bavdaž (Eds.), Proceedings of the BLUE-ETS Conference on burden and motivation in official business surveys. Statistics Netherlands, Heerlen, 22-23 March 2011. Available at: http://www.cbs.nl/NR/rdonlyres/23FD3DF5-6696-4A04-B8EF1FAACEAD995C/o/2011proceedingsblueets.pdf

Wright, B.E. (2004). The role of work context in work motivation: A public sector application of goal and social cognitive theories. Journal of Public Administration Research and Theory, 14, 59-78.

Yancheva, D., \& Iskrova, K. (2011). Reducing the administrative burden for the business in Bulgaria: Single entry point for reporting fiscal and statistical information. In D. Giesen \& M. Bavdaž (Eds.), Proceedings of the BLUE-ETS Conference on burden and motivation in official business surveys. Statistics Netherlands, Heerlen, 22-23 March 2011. Available at: http://www.cbs.nl/NR/rdonlyres/23FD3DF5-6696-4A04-B8EF-1FAACEAD995C/o/2011proceedingsblueets.pdf 